\title{
PEMBERDAYAAN PEREMPUAN MELALUI BINA USAHA EKONOMI KELUARGA 'AISYIYAH (BUEKA)
}

\author{
Dyah Pikanthi Diwanti1), Erna Andriyani2), Rahmadhani Santi Herawati3) \\ Universitas Muhammadiyah Yogyakarta
}

\begin{abstract}
Abstrak
Pemberdayaan perempuan menjadi konsentrasi salah satu organisasi Muhammadiyah. Muhammadiyah sebagai organisasi kemasyarakatan yang bergerak dalam berbagai bidang sangat mendukung upaya pemberdayaan perempuan. Muhammadiyah memiliki berbagai amal usaha, salah satunya pengelolaan badan usaha di organisasi otonom. Melalui Organisasi Otonom yang bergerak dalam ranah keperempuanan yaitu 'Aisyiyah. BUEKA merupakan skema program pemberdayaan ekonomi umat yang diluncurkan oleh Pimpinan Pusat 'Aisyiyah. Skema dirancang untuk memberdayakan Ibu rumah tangga, minimal dapat mempunyai usaha mandiri seperti usaha yang berbentuk home industry. Salah satunya di Pimpinan Cabang 'Aisyiyah Mergangsan. Satu hal yang menjadi fenomena adalah adanya potensi yang luar biasa dari BUEKA yang dikelola oleh PCA Mergangsan dan ini yang menjadi pijakan untuk dijadikan best practise di masyarakarat. Kegiatan yang dilakukan melalui pelatihan, pendampingan dan evaluasi menjadi aset penting dari keberlangsungan dan keberlanjutan BUEKA.Pendekatan penelitian ini dilakukan dengan metode kualitatif sebagai prosedur penelitian yang menghasilkan data deskriptif. Ditinjau dari tema pembahasan dalam penelitian ini tergolong jenis penelitian dengan pendekatan penelitian lapangan yang bersifat studi kasus. Sumber data berasal dari data primer dan sekunder yang diuji dengan teknik triangulasi. Manfaat penelitian bagi akademik adalah menambah wawasan dan bahan pengembangan penelitian, dan bagi praktisi adalah sebagai referensi, sumber informasi dalam pengelolaan BUEKA/ badan usaha baik ditingkatan Aisyiyah maupun ortom lain sekaligus bisa bermanfaat untuk referensi secara umum.
\end{abstract}

Kata Kunci: Pemberdayaan Perempuan, BUEKA (Badan Usaha Ekonomi Keluarga Aisyiyah)

*Correspondence Address : dyahpikanthidiwanti@gmail.com DOI : $10.31604 /$ jips.v6i2.2019.194-207

(C) 2019 Fakultas Keguruan \& Ilmu Pendidikan UM-Tapanuli Selatan 


\section{A. Pendahuluan}

Pemberdayaan merupakan upaya memberikan otonomi, wewenang, atau kepercayaan kepada setiap individu dalam suatu organisasi agar individu tersebut dapat berdaya serta kreatif dalam melakukan segala hal yang akan mendatangkan manfaat untuk dirinya dan orang lain. Pemberdayaan mulai berkembang di Eropa pada abad pertengahan, kemudian terus berkembang hingga tahun 70 -an, 80 -an sampai dengan sekarang. Pemberdayaan terkait erat dengan pembangunan, baik dalam tingkat nasional, atau tingkat daerah sekalipun, pembangunan yang dilakukan yaitu dalam segala aspek seperti aspek sosial, budaya, ekonomi bahkan aspek gender. Pemberdayaan gender dimulai dengan adanya Konferensi Perempuan Internasional di Mexico tahun 1975, Konferensi tersebut membahas tentang diperlukannya partisipasi penuh oleh perempuan dalam pembangunan. Menurut (Puspita: 2016) pemberdayaan perempuan merupakan upaya untuk mewujudkan kesetaraan peran, akses, dan kontrol perempuan serta laki-laki di semua bidang pembangunan. Kesetaraan dalam segala bidang baik perempuan dan lakilaki dimaksudkan dengan tidak adanya diskriminasi antara satu dan lainnya.
Setiap orang baik perempuan dan lakilaki mempunyai kesempatan dan peluang yang sama dalam berbagai kegiatan pembangunan wilayah.

Perkembangan pemberdayaan perempuan di Indonesia atas dasar pemberdayaan berbasis gender di dukung oleh Pemerintah melalui Kementerian Negara Pemberdayaan Perempuan dan Perlindungan Anak (KPPPA) telah mengupayakan berbagai hal dalam meningkatkan peran perempuan dalam kapabilitasnya. Hasil dari peningkatan pemberdayaan perempuan di Indonesia terlihat dalam tabel Indeks Pemberdayaan Gender (IDG) pada tahun 2010-2014 menunjukkan peningkatan.

Berdasar data tabel 1.1 dibawah ini menjelaskan bahwa pada tahun 2010 IDG menunjukkan angka 68,15 persen, naik menjadi 69,14 persen pada tahun 2011. Pada tahun 2012 mengalami peningkatan menjadi 70,07 persen. Tahun 2013 naik menjadi 70,46 persen dan pada tahun 2014 mengalami peningkatan menjadi 70,68 persen. Peningkatan IDG dari 2010-2014 menunjukan bahwa peran perempuan dalam pengambilan keputusan dalam kegiatan ekonomi semakin baik dan potensial. (KPPPA, 2015). 
Tabel 1.1 Tren IDG Indonesia tahun 2010-2014

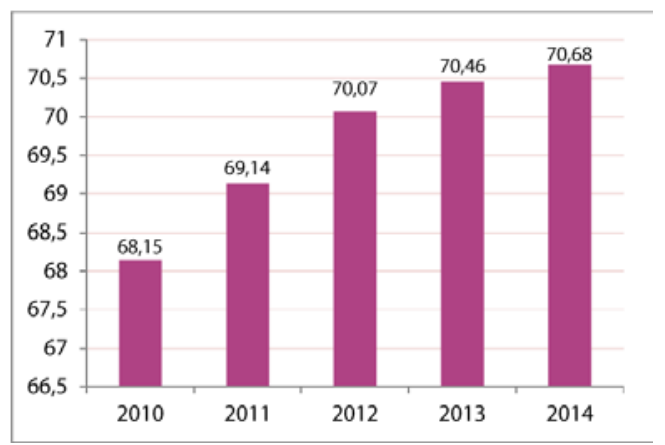

Sumber : BPS

Pemberdayaan

perempuan menjadi konsentrasi salah satu organisasi Muhammadiyah.

Muhammadiyah sebagai organisasi kemasyarakatan yang bergerak dalam berbagai bidang, seperti pendidikan, sosial, ekonomi, budaya dll. Bukti bahwa Muhammadiyah memiliki berbagai amal usaha, antara lain perguruan tinggi, sekolah-sekolah baik dari tingkat Sekolah Dasar (SD), Sekolah Menengah Pertama (SMP) dan Sekolah Menengah Atas (SMA), Muhammadiyah juga mempunyai amal usaha berupa Rumah Sakit, Panti Asuhan, Lembaga Amil Zakat dan masih banyak lagi yang tersebar di Indonesia. Melalui Organisasi Otonom yang bergerak dalam ranah keperempuanan yaitu 'Aisyiyah. 'Aisyiyah merupakan organisasi perempuan Muhammadiyah, yang sering kali disebut sebagai organisasi otonom Muhammadiyah dikarenakan mampu menggerakkan organisasinya dengan mandiri namun masih dalam naungan Muhammadiyah. Sama halnya dengan Muhammadiyah, 'Aisyiyah juga memiliki keanggotaan maupun simpatisan yang tersebar di seluruh daerah dan wilayah di Indonesia. Gerak langkah Aisyiyah juga dalam berbagai aspek seperti pendidikan, Ekonomi, Sosial, Budaya dll, Pada laporan organisasi otonom dalam Muktamar ke47 di Makassar disebutkan bahwa Keanggotaan 'Aisyiyah periode 20102015 dari mulai tingkat ranting, cabang, daerah, wilayah mengalami peningkatan. Berikut data keanggotaan 'Aisyiyah yang tersebar di seluruh Indonesia :

- Pimpinan Wilayah (Centre) : 34 Wilayah

- Pimpinan Daerah (Distric): 435 Daerah

- Pimpinan Cabang (Branch): 2.922 Cabang

- Pimpinan Ranting (Grassrote): 9.522 Ranting

- Pimpinan Cabang (Special Branch): 4 cabang Istimewa (Luar Negeri) Banyaknya jumlah keanggotaan yang tersebar diseluruh Indonesia menjadi aset besar yang dimiliki 'Aisyiyah. Potensi tersebut perlu dimanfaatkan sebaik-baiknya agar dapat memberikan manfaat yang sebesar- 
besarnya bagi kepentingan organisasi khususnya, dan masyarakat Indonesia umumnya. Keanggotaan yang tersebar diseluruh Indonesia tesebut juga menjadi potensi dilakukan pemberdayaan perempuan, yang pada dasarnya keanggotaan 'Aisyiah yaitu kaum perempuan. Menurut Julia Cleves Moses (1996) pada bukunya yang berjudul "Gender dan pembangunan" telah dijelaskan bahwa pemberdayaan lebih terkait dengan pendekatan dari bawah ke atas (Bottom-up) dari pada pendekatan dari atas ke bawah (TopDown). Hal ini selaras dengan keanggotaan Aisyiyah, pemberdayaan perempuan dilakukan mulai dari tingkat Pimpinan Ranting, dan juga Pimpinan Cabang, agar dapat menyeluruh dirasakan oleh setiap anggota lingkup kecil dan juga dalam lingkup keluarga. Telah dijelaskan sebelumnya bahwa gerak langkah 'Aisyiyah sangat luas, yaitu dalam bidang sosial kemasyarakatan, ekonomi, kesehatan, pendidikan, hukum, serta dakwah dan pengkaderan dan masih banyak lagi. Untuk terus menggerakkan sebuah organisasi, diperlukan biaya yang tidak sedikit, sementara sampai saat ini masih banyak wilayah, daerah, cabang hingga ranting 'Aisyiyah yang tidak memiliki sumber keuangan yang mandiri. Salah satu langkah yang bisa mendorong kemandirian organisasi 'Aisyiyah adalah dengan membangun kemandirian ekonomi organisasi berbasis ekonomi keluarga yaitu melalui Bina Usaha Keluarga 'Aisyiyah (BUEKA).

BUEKA merupakan skema program pemberdayaan ekonomi umat yang diluncurkan oleh Pimpinan Pusat 'Aisyiyah. Skema dirancang untuk memberdayakan ibu rumah tangga, minimal dapat mempunyai usaha mandiri seperti usaha yang berbentuk home industri. Langkah 'Aisyiyah sebagai organisasi perempuan Muhammadiyah telah berhasil memfasilitasi setiap anggotanya dalam suatu wadah pemberdayaan ekonomi perempuan berbasis ekonomi keluarga yaitu Bina Usaha Ekonomi Keluarga 'Aisyiyah (BUEKA).

Selanjutnya, alasan mengapa peluncuran BUEKA ini juga tidak lain karena fenomena masyarakat menengah kebawah sering menjadi korban kebijakan pemerintah maupun kebijakan global disebabkan lemahnya pengetahuan dan jaringan masyarakat bawah menjadi sasaran tengkulak atau pemilik modal untuk diekploitasi. Padahal jika masyarakat memiliki pengetahuan dan jaringan yang bagus, akan mengurangi problem ekonomi 
tingkat keluarga maupun masyarakat (Puspita Handayani, 2016). Disinilah peran 'Aisyiyah dengan potensi yang ada di tingkat Cabang dan juga Ranting untuk mengembangkan usaha rakyat, selain sebagai media dakwah juga dapat membantu masyarakat dalam meningkatkan ekonomi.

Penelitian ini mengambil sebagian peran organisasi'Aisyiyah dalam bidang pemberdayaan ekonomi perempuan, karena 'Aisyiyah berpendirian bahwa harkat martabat perempuan Indonesia tidak akan meningkat tanpa peningkatan kemampuan ekonominya. Salah satunya di kota Yogyakarta yaitu tepatnya di Cabang 'Aisyiyah Mergangsan. Program kerja Bina Usaha Ekonomi Keluarga 'Aisyiyah (BUEKA) telah dilaksanakan di Cabang Mergangsan, yang terdapat beragam usaha industri rumahan seperti usaha catering, snack, kerajinan tangan berupa manik-manik, bross ataupun kerajinan membuat tas rajut dari benang, tas rajut dari limbah rumah tangga seperti kantong plastik dan masih banyak lagi hasil kerajinan tangan dari ibu-ibu PCA Mergangsan. Dari penjelasan latar belakang masalah diatas memunculkan ide kreatif peneliti dengan mengambil judul penelitian yaitu "PEMBERDAYAAN EKONOMI
PEREMPUAN MELALUI BINA USAHA

EKONOMI KELUARGA AISYIYAH (BUEKA) (Studi Bina Usaha Ekonomi Keluarga (BUEKA) Pimpinan Cabang Aisyiyah Mergangsan, Kota Yogyakarta).

\section{B. Metodologi}

Penelitian ini merupakan penelitian kualitatif deskriptif. Penelitian kualitatif bertujuan untuk mendapatkan pemahaman tentang kenyataan melalui berfikir induktif, yang penelitian tersebut membangun dan mengembangkan konsep, teori dan model data lapangan (Nawari, 2015:95). Melalui penelitian kualitatif, peneliti dapat mengenali subyek, merasakan apa yang dialami dalam kesehariannya (Basrowi dan Suwandi, 2008:2). Pendekatan deskriptif, yaitu suatu metode dalam meneliti suatu kelompok, objek, atau kondisi, suatu sistem pemikiran, ataupun peristiwa pada masa sekarang (Moh Nazir, 2005:54). Data yang dikumpulkan dari pendekatan deskriptif berupa kata-kata, gambar, dokumen. Semua data yang dikumpulkan berkemungkinan menjadi kunci terhadap yang penelitian.

Penelitian ini dilakukan di Pimpinan Cabang 'Aisyiyah Mergangsan, yang beralamat di Jalan Karangkajen BI MG-3/99755153, Brontokusuman, Mergangsan, Yogyakarta 55153. Subyek 
penelitian ini meliputi informan pangkal dan informan kunci. Informan pangkal adalah pihak Pimpinan Cabang 'Aisyiyah Mergangsan, khusunya dari Majelis Ekonomi \& Ketenagakerjan yang memahami secara umum tentang kegiataan pemberdayaan ekonomi perempuan dan kegiatan Bina Usaha Ekonomi Keluarga 'Aisyiyah (BUEKA). Adapun untuk informan kunci, yaitu meliputi Ketua Majelis Ekonomi \& Ketenagakerjaan periode kepemimpinan pada masa perintisan serta masa lanjutan dan anggota BUEKA yang mempunyai usaha.

\section{Literatur Review}

Penelitian yang dilakukan oleh Desy Marlina tahun 2017 tentang Pemberdayaan Perempuan melalui program usaha Peningkatan Pendapatan Keluarga Sejahtera ( Studi Kasus UPPKS Mekarsari Dusun Wonocatur, Banguntapan Bantul). Hasil penelitian ini yakni UPPKS Mekarsari menggunakan tahapan dalam melakukan pemberdayaan antara lain faktor kultural dan faktor struktural. Dalam peneitian ini menggambarkan sebuah pendekatan kultural dan struktural yang membuat secara sosiologi UPPKS Mekarsari pemberdayaan mampu dilakukan. Sama halnya dalam penelitian ini dilakukan pendekatan secara kultural dengan pembiasaan anggota yang melakukan kegiatan rutin dan secara struktural melalui pimpinan organisasi. Selain itu terdapat juga penelitian yang dilakukan oleh Nur Hidayah tahun 2016 dengan judul Evaluasi Pelaksanaan program Ibu Mandiri Dalam Pemberdayaan Perekonomian Kaum perempuan (Studi Kasus Yayasan Sahabat Ibu Yogyakarta priode 2014). Hasil penelitiannya adalah dengan membandingkan dan mengevaluasi suatu program adanya Ibu Mandiri sesudah dan sebelum program dilaksanakan. Sama halnya dalam penelitian BUEKA di PCA Mergangsan ini,program BUEKA dilaksanakan dalam periode yang berkelanjutan dengan capaian.

Selain itu secara teori terdapat beberapa diantaranya pengertian umum studi perempuan yaitu segala sesuatu yang fokus pembahasannya tentang perempuan, baik tentang sejarah dari perempuan, tentang faktor-faktor yang mempengaruhi posisi perempuan di masyarakat yang berbeda-beda, tentang peran perempuan dalam pembangunan (Ratna Saptari, 1997:45). Permasalahan perempuam di bidang ekonomi tidak terlepas dari masalah kemiskinan. Tiga pendekatan kemiskinan yaitu: pertama, 
kemiskinan kultural yang mana kemiskinan masih dipengaruhi oleh budaya tradisional dengan terbatasnya perempuan dalam mendapatkan akses dalam memperoleh penghasilan. Kedua, kemiskinan struktural, adanya kemiskinan struktural ini diakibatkan oleh kemiskinan kultural karena rendahnya pendidikan dan rendahnya ketrampilan perempuan sebagian besar perempuan yang berada diwilayah pedesaan. Ketiga, kemiskinan alamiah menjelaskan bahwa sebagian perempuan yang bersikap pasrah terhadap posisi dirinya dalam kehidupan rumah tangga dan masyarakat.

Pemberdayaan

(Empowerment) merupakan proses perubahan pribadi karena masingmasing individu mengambil tindakan atas nama diri mereka sendiri dan kemudian mempertegas pemahamannya terhadap dunia. Pemberdayaan merupakan suatu proses yang menyangkut hubungan kekuatan (kekuasaan) yang berubah antara individu, kelompok dan lembaga sosial lainnya (Shrangge, 1993 dalam buku Women in Public Sector). Penelitian lain dari Elisa Ferdiyanti tahun 2015 berjudul Peran Wanita Dalam Pengembangan Ekonomi Rumah Tangga di Sekitar PDP Dusun Sumberwadung
Desa Harjomulyo. Hasil Penelitian ini menyebutkan bahwa pemberdayaan ekonomi perempuan dilakukan melalui ekonomi kreatif.

\section{Pembahasan}

Organisasi 'Aisyiyah merupakan organisasi Muhammadiyah yang didirikan oleh Muhammadiyah pada 19 Mei 1917, dalam perkembangannya sejak Muktamar tahun 2005 menjadi organisasi otonom khusus dari Muhammadiyah. Hal ini berarti seluruh anggota 'Aisyiyah adalah anggota Muhammadiyah yang diberikan wewenang menyelenggarakan amal usaha yang ditetapkan oleh pimpinan Muhammadiyah dalam koordinasi pembantu pimpinan yang sesuai dengan ketentuan yang berlaku tentang amal usaha tersebut (pasal 2, Ad/ART 'Aisyiyah, hlmn. 6). PCA Mergangsan memiliki beberapa amal usaha diantaranya: TK ABA Mergangsan, Musholla 'Aisyiyah, Taman Asuh (Kelomok Bermain) 'Aisyiyah Pelita Hati, Taman Pendidikan Al-Qur'an 'Aisyiyah Al Ukhuwah. Dalam menjalankan kegiatan organisasi PCA mergangsang membagi wilayah kepempimpinan sesuai dengan Kelurahan yang ada di Kecamatan Mergangsan. Zonasi kepemimpinan PCA 
Mergangsan antara lain: Kelurahan Brontokusuman, terdiri dari 7 Ranting. PCA Mergangsan memiliki visi dan misi serta struktur organisasi yang terdiri dari Pimpinan Harian dan Badan Pembantu Pimpinan. Pengurus secara struktural inilah yang mengaktualisasikan visi -misi menuju program kerja bersama seluruh anggota ke dalam kegiatan sosial kemasyarakatan. Pada periode muktamar ke 45 di Malang, salah satu program Majelis Ekonomi \& Ketenagakerjaan 'Aisyiyah yaitu menumbuhkan semangat kewirausahaan melalui pengembangan usaha kecil dan menengah sebagai gerakan memberdayakan ekonomi umat. Kemudian program revitalisasi atau penguatan kembali Bina Usaha Ekonomi Keluarga 'Aisyiyah (BUEKA) di seluruh tingkatan. Pimpinan Pusat 'Aisyiyah meluncurkan sebuah skemapemberdayaan yang dinamakan Bina Usaha Ekonomi Keluarga 'Aisyiyah atau popular dengan sebutan BUEKA. Skema ini dirancang untuk memberdayakan kaum ibu rumah tangga untuk sekurang-kurangnya memiliki kegiatan usaha mandiri. BUEKA diharapkan menjadi upaya konkrit dari Pimpinan 'Aisyiyah untuk meningkatkan kapasitas ekonomi yang bisa dilakukan oleh kalangan ibu-ibu. Melalui BUEKA, ibu-ibu bisa menopang kebutuhan rumah tangga, disamping juga mengasah jiwa wirausaha, mencari peluang-peluang baru dalam bidang ekonomi.

Skema pemberdayaan perempuan yang diluncurkan oleh PP 'Aisyiyah menjadi pelopor skema pemberdayaan perempuan yang ada di tiap Pimpinan Wilayah, Pimpinan Daerah, Pimpinan Cabang dan juga Pimpinan Ranting yang ada di seluruh Indonesia. Skema Pemberdayaan perempuan BUEKA memperlihatkan perkembangan dari mulai diluncurkan hingga sekarang. Salah satunya perkembangan pemberdayaan perempuan BUEKA yaitu yang ada di Pimpinan Cabang Mergangsan, Kota Yogyakarta. Pemberdayaan perempuan melalui pembinaan, pendampingan, pelatihan yang dilakukan Majelis Ekonomi \& Ketenagakerjaan dengan program BUEKA memberikan banyak manfaat untuk ibu-ibu di Cabang Mergangsan. Pemberdayaan perempuan melalui BUEKA PCA Mergangsan terbukti menambah pengalaman, keterampilan, serta wawasan untuk memulai atau mengembankan usaha. Sedikit banyak dari ibu-ibu anggota BUEKA telah 
memiliki usaha rumahan yang bisa menambah pemasukan untuk keluarga Masa perintisan sebenarnya dimulai sebelum kepemimpinan 2005-2010. Namun, Sebenarnya untuksoft Launching BUEKA oleh Pimpinan Pusat'Aisyiyah telah dimulai sekitar tahun 1999, tetapi terdapat revisi sehingga baru dilakukan grand launching pada Muktamar ke 45 di Malang tahun 2005 (Wawancara dengan Ibu Nikmah, Ketua MEK PP`Aisyiyah). Kemudian untuk segenap tingkat Kepemimpinan dibawah Kepemimpinan Pusat 'Aisyiyah membentuk BUEKApada tiap kepemimpinan baik tingkat Wilayah, tingkat Daerah,tingkat Cabang, dan tingkat Ranting menyesuaikan setelah adanya Muktamar ke 45 di Malang tersebut.

Latar belakang diadakannya BUEKA di Pimpinan Cabang Aisyiyah Mergangsan yaitu dikarenakan himbauan pembentukan BUEKA ditiap wilayah kepemimpinan 'Aisyiyah seluruh Indonesia dan juga karena program pemberdayaan perempuan akan tepat jika diadakn di PCA Mergangsan. Seperti yang disampaikan oleh Ibu Muhsin (Tokoh perintis BUEKA PCA Mergangsan dan Ketua Majelis EKonomi \& Ketenagakerjaan periode sebelum tahun 2005). Bentuk kegiatannya yaitu pelatihan ketrampilan memasak untuk ibu-ibu yang berdomisili di Mergangsan. Yang mana kegiatan pelatihan ketrampilan memasak ini tetap berlanjut hingga sekarang. Merintis BUEKA di PCA Mergangsan menjadi salah satu langkah tepat agar dapat menumbuhkan semangat berwirausaha untuk ibu-ibu di Cabang 'Asiyiyah Mergangsan.

Kegiatanya pemberdayaan pada masa perintisan pun belum mengatasnamakan kegiatan dari BUEKA, namun kegiatannya mengarah ke kegiatan pemberdayaan ekonomi perempuan. kegiatannya yaitu pelatihan ketrampilan memasak. Untuk tempat dilangsungkan di sekretariat PCA Mergangsan yang dulunya yaitu Klinik bersalin BKIA 'Aisyiyah. Sekarang BKIA beralih fungsi menjadi Asrama Putri Mts Muhammadiyah Mergangsan dan sebagian tempat menjadi sekretariat PCA Me Segenap Pimpinan Cabang 'Aisyiyah Mergangasan mendukung diadakannya BUEKA di Cabang 'Aisyiyah Mergangsan. Namun dukungan yang diberikan hanya dorongan semangat dan dukungan non materil. Mengingat kondisi Cabang yang minim keuangan untuk membantu keuangan guna kegiatan pelatihan BUEKA. Karena memang masalah kebanyakan cabang 
dan juga Ranting di berbagai wilayah yaitu masalah dana operasioal. Maka dari itu diadakannya BUEKA setidaknya dapat membantu keuangan organisasi mungkin dengan infaq yang diberikan oleh ibu-ibu yang mempunyai usaha dengan menyisihkan kelebihan keuntungan yang diperoleh.

Kondisi BUEKA PCA Mergangsan pada masa lanjutan cukup baik bahwasanya ibu-ibu anggota BUEKA lebih paham tentang program pemberdayaan itu sendiri. Seperti penyampaian oleh Ibu Siti Pastumi Irianti (Ketua Majelis Ekonomi \& Ketenagakerjaan PCA Mergangsan). Kegiatan BUEKA mulai dari pelatihan-pelatihan seperti pelatihan memasak/cooking class, pelatihan kerajinan tangan/handycraft, kegiatan lainnya yaitu kajian pengantipelatihan, arisan BUEKA, distribusi produk-produk dari BUEKA yaitu sabun melin (serbuk\&cair), dan juga pendistribusian air minum kemasan merk "Bueka”. Untuk pelatihan memasak dan juga pelatihan kerajinan tangan rutin diadakan setiap hari jumat pahing. Pelatihan setiap pertemuannya pun berbeda, misal pertemuan 1 pelatihan memasak kue bolu, pertemuan 2 pelatihan memasak kue karamel, pelatihan 3 nanti pelatihan kerajinan tangan merajut dsb. Mentor dalam setiap pelatihan pun berbeda karena menyesuaikan pelatihan yang diadakan, dan juga mentor bisa dari anggota BUEKA yang telah menguasai materi pelatihan yang akan di sampaikan kepada rekan-rekannya sesama anggota. Mengenai pendistribusian produk dari 'Aisyiyah yaitu sabun melin (serbuk\&cair) dan air minum kemasan merk "Bueka", untuk setiap keluarga ibu-ibu di ranting dan cabang di himbau untuk membeli melin minimal 1 bulan 1 bungkus/botol, dan untuk air kemasan merk "Bueka" dihimbau untuk tiap ranting membeli minimal 2 box setiap bulannya. Disetiap pendistribusian tersebut ada infaq yang nantinya masuk di kas Cabang dan juga Ranting."

Bentuk pendampingan BUEKA PCA Mergangsang yaitu dengan memantau serta memonitor setiap kegiatan yang BUEKA adakan. Pendampingan tidak hanya sebatas dalam hal kegiatan BUEKA seperti kegiatan pelatihan. Namun juga dalam pendampingan usaha Ibu-ibu anggota BUEKA, dalah hal branding produk atau juga dalam hal packaging. Dalam hal pemasaran, pihak MEK dan juga pendamping BUEKA turut membantu memasarankan produk apabila dari mereka membutuhkan bantuan untuk produknya dipasarkan. 
Meski demikian, terdapat hambatan dalam pengembangan BUEKA di PCA Mergangsan yaitu tentang ketersediaan modal. Diperlukannya modal baik dalam menjalankan opeasional BUEKA itu sendiri atau dalam pengembangan usaha perorang atau perkelompok. BUEKA dinaungi oleh Pimpinan Cabang ‘Aisyiyah Mergangsan, dukungan yang diberikan selama ini baru sebatas non materil. Mengingat kondisi keuangan organisasi yang hal ini juga merupakan problem dari kebanyakan cabang dan juga ranting 'Aisyiyah yang ada di berbagai wilayah. Namun demikian, adanya BUEKA lambat laun malah mampu membantu sedikit keuangan organisasi. Berikut contoh produk yang diproduksi BUEKA Cabang Mergangsan: kuliner, aksesoris, kerajinan dan beberapa yang lain.

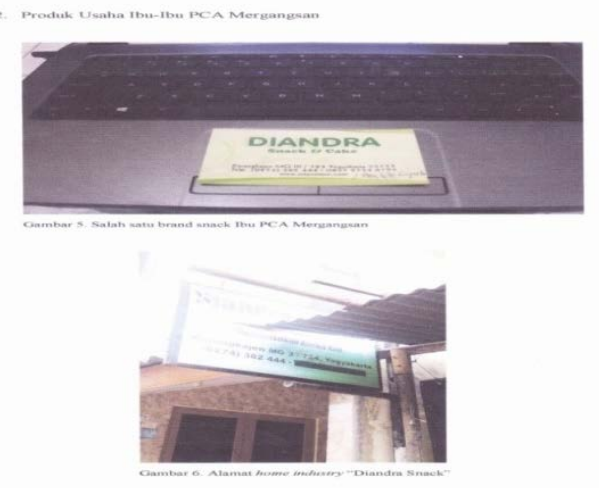

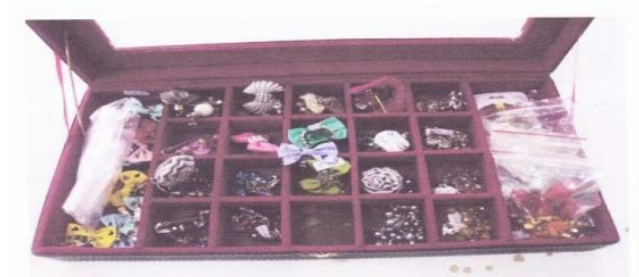

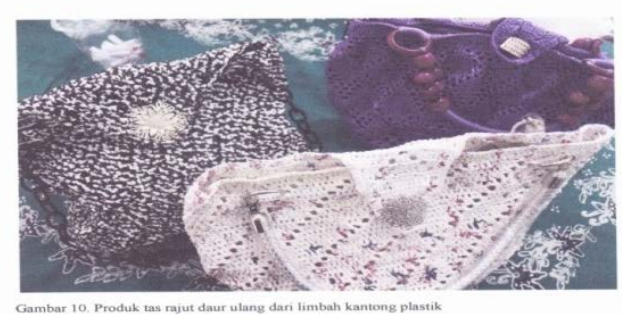

\section{E. Simpulan}

Berdasarkan penelitian dan pengamatan di lapangan mengenai Pemberdayaan Ekonomi Perempuan Melalui Bina Usaha Ekonomi Keluarga 'Aisyiyah Pimpinan Cabang 'Aisyiyah Mergangsan, Yogyakarta, sebagaimana yang telah diuraikan, maka peneliti dapat mengambil kesimpulan sebagai berikut:

1. Pemberdayaan ekonomi perempuan BUEKA PCA Mergangsan melalui dua masa yaitu masa perintisan dan masa lanjutan. Pada masa perintisan menekankan kepada pengenalan BUEKA dengan kegiatan yang masih terbatas. Sedangkan dalam masa lanjutan telah rutin di adakan berbagai pelatihan ketrampilan, dan juga beberapa anggota telah mempunyai usaha yang mereka praktikkan setelah mengikuti pelatihan dari BUEKA. Hal ini 
Dyah Pikanthi Diwanti, Erna Andriyani, Rahmadhani Santi Herawati

Pemberdayaan Perempuan Melalui Bina Usaha Ekonomi Keluarga 'Aisyiyah (BUEKA)

menjadi bukti bahwa BUEKA PCA Mergangsan berhasil membantu anggota dalam pengembangakan minat dan juga bakat anggota, dengan anggota mempunyai usaha sendiri mereka dapat membantu perekonomian keluarga.

2. Proses pendampingan Bina Usaha Ekonomi Keluarga 'Aisyiyah PCA Mergangsan yaitu dengan monitoring setiap usaha yang dijalankan anggotanya yaitu dengan membantu dalam proses branding, packaging, dan marketing.

\section{Daftar Pustaka}

Ainiyah, Qurrotul. 2015. Keadilan Gender dalam Islam: Konvensi PBB dalam

Pespektif Mazhab Shafi'i. Malang: Intrans Publishing.

Baidan, Nashiruddin. 1999. Tafsir bi Al-Ra'yi: Upaya Penggalian Konsep Wanita dalam Al Qur'an, Mencermati Konsep Kesejajaran Wanita dalam Al Qur'an. Yogyakarta: Pustaka Pelajar.

Hasyim, Syafiq. 2001. Hal-hal yang Tak Terpikirkan tentang Isu-isu Keperempuanan dalam Islam. Bandung: Mizan.

Ismail, Nawari. 2015. Metodologi Penelitian untuk Studi Islam. Yogyakarta: Samuder Biru.

Mosse, Julia Cleves. 1996. Gender dan Pembangunan. Yogyakarta: Pustaka Pelajar.
Koentjoro. 2014. Metodologi Penelitian Kualitatif untuk ilmu-ilmu sosial. Jakarta: Salemba Humanika.

Mernisi, Fatima dan Riffat Hassan. 1995. Perempuan dan Laki-laki dalam Yogyakarta: Yayasan Prakarsa.

Moleong, Lexy J.. 2002. Metodologi Penelitian Kualitatif. Bandung: PT Remaja Rosda Karya.

Murniati, A Nunuk. 2004. Getar Gender. Magelang: Indonesia Tera.

Nugroho, Ruslan. Gender dan Strategi Pengarusutamannya di Indonesia. 2008.Yogyakarta: Pustaka Pelajar.

Ruslan, Murniati. 2010. Pemberdayaan Perempuan Dalam Dimensi Pembangunan Berbasis Gender. Hal: 79-96.

Aslichati, Lilik. Organisasi Pemberdayaan dan Kesejahteraan Keluarga Sebagai Sarana Pemberdayaan Perempuan. 2015. Jurnal Organisasi dan Manajemen Vol. 7.

Harsosumarto, Sri Lestari. Koperasi dan Pemberdayaan Perempuan. 2015. Jurnal INFOKOP Vol. 15.1, No 13.

Hidayah, N. 2017. Evaluasi Pelaksanaan Program Ibu Mandiri (PRIMA) dalam Pemberdayaan PErekonomian Kaum Perempuan di Yayasan Sahabat Ibu Yogyakarta Periode 2014. Jurnal Pendidikan dan Ekonomi,6(2)Jati, Waluya. Analisis Motivasi Wirausaha Perempuan (Wirausahawati) di Kota Malang. 2012. Jurnal Humanity Vol 4.2.

Karsidi, Ravik. Pemberdayaan Masyarakat untuk Usaha Kecil dan Mikro (Pengalaman Empiris di Wilayah Surakarta Jawa Tengah). 2007. Jurnal Penyuluhan, 3(2). 
Marwati, dkk. Model Pemberdayaan Perempuan Melalui Pengembangan Kewirausahaan Keluarga Menuju Eonomi Kreatif Di Kabupaten Karang Anyar. 2012. Jurnal SEPA Vol. 9.1 No. 134-144.

Prama, Crisvi. Faktor-faktor yang Mempengaruhi Keberhasilan Pemberdayaan Perempuan Desa Joho di Lereng Gunung Wilis. 2013. Jurnal Kebijakan dan Manajemen Publik 1.01

Prawoto, Nano. Model Pengembangan dan Pemberdayaan Masyarakat Berbasis Kemandirian untuk Mewujudkan Ketahanan Ekonomi dan Ketahanan Pangan (Strategi Pemberdayaan Ekonomi pada Masyarakat Dieng di Propinsi Jawa Tengah). 2012. Jurnal Organisasi dan Menejemen Vol 8, No 2, pp. 135-154.

Saptandari, Pinky. Lima Tingkat Pemberdayaan Perempuan. 2010. Jurnal Masyarakat Kebudayaan dan Politik 12, No. 2. Hlm, 3338.

Anggraini, Ayu. 2017. Peran Dekranasda Kota Tanjung Balai dalam Pemberdayaan Ekonomi Ibu Rumah Tangga Melalui Home Industry Kulit Kerang di Kelurahan Perjuangan Kecamatan Teluk Nibung (Doctoral Dissertation, Universitas Islam Negeri Sumatera Utara).

Farhan, Dimas Abu. 2017. Pemberdayaan Kaum Perempuan Guna Meningkatkan Pendapatan Keluarga dalam Prespektif Ekonomi Islam (Studi padakelompok wanita tani sekarmulya, Desa Astomulyo, Kecamatan Punggur, Kabupaten Lampung Tengah) (Doctoral Dissertation, UIN Raden Intan Lampung).
Ferdiyanti, Elisa. 2015. Peran Wanita dalam Pengembangan Ekonomi Rumah Tangga di Sekitar PDP Dusun Sumberwadung Desa Harjomulyo Kecamatan Silo.

Garnasih, Rahmi. 2011. Peran Modal Sosial dalam Pemberdayaan Perempuan pada Sektor Informal (Studi Kasus Pada Pedagang Warung Nasi).

Handayani, Puspita. 2016. Aisyiyah dan Ekonomi Kreatif: Usaha Pemberdayaan Perempuan Melalui Pengembangan Kewirausahaan Keluarga di Kecamatan Tangulangin Kabupaten Sidoarjo. HIm. 368-393.

Manihuruk, Rani Deswita. 2018. Efektivitas Program Kampung Sejahtera Mandiri dalam Pemberdayaan Perempuan Rawan Sosial EKonomi oleh Yafsi di Kelurahan Aur Medan.

Panduan BUEKA, Majelis Ekonomi Pimpinan Pusat 'Aisyiyah

Parawansa, Khofifah Indar. Pembedayaan Perempuan Dala m Pembangunan Berkelanjutan. Bali, hlm (2003): 1-15.

Perempuan, Kementerian Pemberdayaan, Perlindungan Anak, dan Badan Pusat Statistik. 2012.Pembangunan Manusia Berbasis Gender.

Rohmah, Nurul Lailatur. 2016. Pemberdayaan Perempuan Pesisir dalam Pengelolaan Ikan Laut untuk Meningkatkan EKonomi Keluarga (Studi Kasus Desa Purworejo, Bonang, Demak, Jawa Tengah). PhD diss., IAIN Purwokerto, 2016).

Tanfidz Muktamar Muhammadiyah ke 47 Makassar. 